\title{
Language symptoms of developmental language disorders: An overview of autism, Down syndrome, fragile $X$, specific language impairment, and Williams syndrome
}

\author{
MABEL L. RICE, STEVEN F. WARREN, and STACY K. BETZ \\ University of Kansas
}

\section{ADDRESS FOR CORRESPONDENCE}

Mabel L. Rice, University of Kansas, Child Language Doctoral Program, 1000 Sunnyside Avenue, 3031 Dole Center, Lawrence, KS 66045-7555. E-mail: mabel@ku.edu

\begin{abstract}
Language deficits occur in a variety of developmental disorders including autism spectrum disorders, Down syndrome, fragile $\mathrm{X}$ syndrome, specific language impairment, and Williams syndrome. This paper describes the specific pattern of linguistic deficits in each of these disorders in terms of speech production, semantic, and syntactic abilities as well as the relationship between cognitive and linguistic skills and the presence of a deviant or delayed pattern of development. In the spirit of synthesis across diverse literatures, preliminary comparisons among the language profiles of these disorders are made. The full picture, however, is incomplete given the current state of the literature, which tends to focus on the analysis of a narrow range of linguistic phenomena within a single disorder. The field is in need of research that systematically compares these disorders and leads to detailed descriptions of linguistic phenotypes of each disorder.
\end{abstract}

The study of children with language disorders has a long and rich history. Language disorders are widely recognized as hallmark symptoms of an array of developmental clinical conditions. The research literature is generally organized according to diagnostic category, usually with the aim of describing the language disorders of a particular clinical group, for example, autism spectrum disorders, Down syndrome, fragile X syndrome, specific language impairment (SLI), or Williams syndrome. There are fewer investigations involving pairwise comparisons across conditions to determine if language and/or cognitive profiles are the same or different across clinical groups. Rice and Warren (2004) argue that there is a current need for careful consideration of the ways in which language disorders are manifest across clinical conditions, given the momentum in genetic and biobehavioral 
Rice et al.: Language symptoms of developmental language disorders

investigations within each disorder, the broader implications across disorders, and the lack of a current synthesis.

The purpose of this paper is to provide an overview of what is known or under investigation across the clinical conditions listed above. This summary and synthesis draws heavily on the chapters of Rice and Warren (2004), which were written by scientists who have programmatic investigations underway in one or more of the clinical groups. Readers interested in further detail are encouraged to consult the edited volume for more complete literature reviews. In the context of this Special Issue of Applied Psycholinguistics, the following overview provides background for the other papers in this collection that presuppose some of the content found in Rice and Warren (2004) in the discussions of future research directions.

\section{THE SIGNIFICANCE OF SHARED SYMPTOMS OF LANGUAGE DISORDERS}

To the extent that language impairments are manifest in diverse clinical conditions, an understanding of what is common across conditions will help clarify the symptoms of each condition, as well as clarify the nature of language impairments and the ways in which the human language capacity is vulnerable. Investigations of genetic, neurocognitive, and molecular mechanisms require precise description of the behavioral manifestations of language impairments that in turn are essential in the definition of clinical groups or subgroups within a clinical diagnosis. Although the modern studies of Down syndrome, Williams syndrome, and fragile $\mathrm{X}$ syndrome have provided very precise information about genetic etiologies at the molecular level, the exact ways in which the biological differences contribute to language impairment are unknown. On the other hand, the search for the genetic contributions to autism has been inconclusive. Some investigators argue that the inconclusiveness is attributable at least in part to a broad diagnostic category for autism spectrum disorders that includes both children who have language impairments and children who do not show language impairment. It is possible that subtyping according to language competencies within the broad clinical diagnosis of autism spectrum disorders may provide greater power in the genetics analyses. The studies of children with SLI have provided relatively precise details about the nature of the children's language impairments, although the investigations of etiological factors are at early, and inconclusive, stages of inquiry.

There are two possible approaches to investigation, both of which require an understanding of language symptoms within and across conditions. These approaches are described as top-down versus bottom-up. Although an ideal program of investigation would include both approaches, in converging investigations of language symptoms and etiological factors, individual studies are usually constrained to one approach. In Smith and Morris (2005; see also Smith, 2004; and Morris, 2004), the two approaches to genetics studies are described in terms of how to define the starting point of investigation: a top-down approach would focus on precise specification of the language phenotype to search for genes affecting specific language disorders; a bottom-up approach would focus on the language phenotypes in known genetic syndromes as models of gene effects. Fisher's paper 
Rice et al.: Language symptoms of developmental language disorders

in this issue (2005) illustrates how a fortuitous bottom-up approach led to a gene discovery that in turn now guides molecular investigations of the symptoms.

The top-down versus bottom-up approaches are also differentiated in neurocognitive studies. Müller (2005; see also Müller, 2004) differentiates them in this way: a top-down approach begins with an optimal phenotypic description of a disorder and then aims for a biological and developmental understanding. A bottom-up approach focuses on potential etiological pathways and aims to explain complex outcome phenotypes such as language impairments in terms of "elementary developmental disturbances." He argues for the latter approach, focusing on early-emerging sensorimotor impairments as a possible contribution to subsequent language impairments. He also notes that a "conjunction approach" is possible, in which delineated linguistic subcomponents are studied in different clinical groups for the purpose of detecting shared pathological pathways that contribute to the impairment, even though the disorders may differ in other etiological components. He expects that this could be a productive strategy for some subtypes of disorders such as SLI or autism, but not all disorders. In contrast, Phillips (2005) argues for the top-down approach, with a focus on the language phenotypes of different clinical groups and the ways in which electrophysiological brain measures could help clarify the language phenotypes (see also Phillips, 2004, for a discussion of the linguistic phenotypes).

\section{GENERAL THEMES ACROSS DIFFERENT CLINICAL CONDITIONS}

Three general issues appear throughout the literature on language disorders. The first is the language system itself. Many studies employ omnibus standardized tests to determine a child's performance levels, relative to age expectations. Available tests often provide separate estimates of expressive versus receptive language, thereby providing a breakdown according to response modality (where "expressive" tasks require a child to generate a verbal response and "receptive" tasks require nonverbal responses, such as pointing to pictures). Orthogonal to the modality dichotomy are individual elements of the linguistic system. At the generic level, three domains have appeared repeatedly in the literature: phonology/speech production; semantics; and syntax/grammar. Phonology and speech production are often considered at a relatively broad level, such as the general intelligibility of spoken language or the number of spoken sounds pronounced correctly. For the following review, this broad view will be the level intended unless indicated otherwise. Investigations of semantics often focus on lexical vocabulary, usually at the very earliest stages of vocabulary growth and/or indexed by performance on standardized tests of receptive vocabulary levels. Relatively little information is available on the semantics of argument structure, with some noteworthy exceptions, that will be noted. In general, the following overview will be at the broad level of lexical vocabulary development, indexed to age norms. Conventionally, the measures of syntax/grammar have been derived by omnibus language tests where various linguistic structures are aggregated into an overall summary score. Within the last decade there has been considerable interest in morphosyntax, in the particular domain of finiteness marking in clauses. This has been inspired at least in part by developments in linguistic theory, where multiple investigators 
Rice et al.: Language symptoms of developmental language disorders

focused on young children's control of finiteness marking as a way of better understanding how young typically developing children acquire fundamental clause structures (cf. Guasti, 2002). Wexler's (1994) theoretical work included predictions for English-speaking children, which Rice and Wexler and colleagues (cf. Rice, Wexler, \& Cleave, 1995), in an ongoing program of investigation, examined as a clinical marker for language disorders in children with SLI. Currently, the domain of morphosyntax has inspired a growing literature aimed at specific details of clause structures, at the level of particular linguistic details across different forms of language disorders. Almost all of these investigations are at relatively early stages of inquiry, with experimental measures of children's performance. One standardized test is now available for normative information in this domain for the ages 3-8 years (Rice \& Wexler, 2001). This review will focus on English-speaking children, given the length constraints, although the literature now includes many studies of children with language disorders speaking languages other than English (cf. Levy \& Schaeffer, 2003).

The second general issue is whether the language symptoms appear to be "delayed" or "deviant" relative to normal development. Although this issue has been most explicitly investigated for the condition of SLI, it is also intrinsic to the interpretive issues that apply to other conditions of language disorders. In the delayed scenario, the language impairments can seem to share many points of similarity with younger, typically developing children, as if the language system is chronologically guided such that by a certain age level typically developing children have acquired a set of particular language skills, whereas the language of children with language impairments reflects a less mature pattern very similar to younger children. In contrast, in the deviant scenario the language system of children with language impairments might not parallel that of younger children. Instead, the kinds of errors and limitations in language use and competency are inconsistent with what is known about any given level of typical language acquisition. The distinction between delayed and deviant bears on interpretation of the language impairment and possible etiological considerations: Are the linguistic systems of affected children fundamentally similar to unaffected children, or are the systems fundamentally different? Are underlying neurocognitive processes and mechanisms fundamentally similar or different? This issue will be highlighted when appropriate in the following review.

The third general issue is the relationship between language impairments and general levels of nonverbal cognitive skills. This issue appears repeatedly in the literature, as part of the broader question of the nature of language and cognition. The extent to which these two domains are inherently singular or modular remains unresolved and controversial. Many of the studies of children with language impairments who also do or do not display cognitive impairments are motivated by the interest in this broader issue. At the descriptive level, there is great interest in profiling a child's performance across linguistic and cognitive domains, to determine if the domains are similar or discrepant in levels of performance. Levels of performance are often benchmarked to chronological or mental age expectations. At the etiological level, studies of the genetics of language disorders take up the question of whether there is a single underlying genetic factor or if multiple factors are implicated (cf. Viding et al., 2003), and studies of neurocognition examine 
Rice et al.: Language symptoms of developmental language disorders

performance in the two domains to determine if neurocognitive mechanisms are shared or discrepant. This is a pervasive issue in much of the available literature, and will be noted frequently in the following overview.

The following review takes up the different clinical conditions in this order: SLI, autism spectrum disorders, fragile X, Williams syndrome, and Down syndrome. The order was determined by explicatory convenience in laying out the common themes and contrastive comparisons across clinical conditions.

\section{SLI}

This disorder is one in which children perform below age expectations on language measures despite having adequate cognitive and sensory skills for typical development. SLI is usually diagnosed using a set of inclusionary and exclusionary criteria including performance at least 1 standard deviation below age expectations on an omnibus language measure, nonverbal intelligence at or above age expectations, no hearing loss, no known neurologic impairment, and no diagnosis of autism. In contrast to the other disorders described in this article, language impairment is the defining feature of SLI. For this reason, much of the research concerning SLI has focused on describing and/or explaining the linguistic characteristics of this population.

\section{Speech and language}

A long-standing question is whether speech and language impairments are closely linked in children with SLI. This question has two implications. One is whether the speech system (usually operationally defined as the speech production system) is intrinsically linked at deeper levels to the underlying linguistic representations and processing systems. The second is the extent to which independent measurement of speech and morphological development is possible, given that omission of morphemes such as the $-s$ in "writes" could be for reasons of speech production or morphological limitations. In an epidemiologically ascertained sample of children with SLI, definitive evidence was reported that the two dimensions are not intrinsically linked. The comorbidity of speech delay with SLI was less than 2\% (Shriberg, Tomblin, \& McSweeny, 1999). A related finding by Zhang and Tomblin (2000) is that children with speech disorders are more likely than children with language disorders to be served by speech-language pathologists. The combination of these two studies suggests that clinical caseloads or research studies using clinically ascertained samples of children with SLI may be biased toward children with both speech disorder and SLI, while in the actual population the true prevalence of speech disorder in children with SLI is low. In the overview below, we see that a disconnect between speech and language is a general observation in other clinical groups as well.

\section{Vocabulary}

With regard to vocabulary/lexical development, there is extensive documentation that children with SLI are likely to perform below age peers (cf. Leonard, 1998). 
Rice et al.: Language symptoms of developmental language disorders

Of interest here, for the purpose of comparison to other clinical conditions, is the extent to which first words are delayed in appearance for children with SLI. This is a relatively unexplored area, given that this disorder is usually not identified until the preschool years or later. A handful of prospective studies have looked at children known as "late talkers" and their subsequent outcomes at later stages of development (cf. Paul, 1996; Rescorla, 2002, 2003; Whitehurst \& Fishel, 1994). Although the evidence is inconclusive, Paul (1996) reported $26 \%$ of the late talkers were affected at ages 6-7 years. Tager-Flusberg and Cooper (1999) called for further studies of late talkers as antecedent conditions for SLI. One retrospective study of children with SLI found that production of early words and first word combinations was delayed (Trauner, Wulfeck, Tallal, \& Hesselink, 1995). At older ages, children with SLI perform below age-matched peers but similarly to younger children on receptive vocabulary measures, indicating a delayed lexical system (Rice, 2003, 2004a, 2004b).

\section{Morphology/morphosyntax}

The domains of morphology and morphosyntax have long been known to be areas of weakness for children with SLI. The optional infinitive (Wexler, 1994, 1998) and extended optional infinitive theories (Rice et al., 1995; Rice \& Wexler, 1996) provide an explanation for why typically developing children and children with SLI have prolonged difficulty with some morphemes but not others. The distinction focuses on whether or not the morpheme represents grammatical features of the syntax, including tense and agreement, which play a part in syntactic movement operations. In English, much attention has been given to the morphemes that denote grammatical finiteness of a sentence, and are therefore considered morphosyntactic in nature. These morphemes include third person singular $-s$, past tense $-e d$, irregular past tense forms, copula be, and auxiliary be and do. Other morphemes, such as plural $-s$, that do not involve syntactic features are not considered part of the morphosyntactic system. Therefore, comparison of morphemes that are and are not related to the finiteness system can help determine the specific nature of morphologic difficulties in children with developmental language disorders.

Children with SLI differ from both age-matched controls and younger, language-matched controls in terms of their use of and grammaticality judgments of finiteness morphemes (Rice, 2003, 2004a, 2004b; Rice \& Wexler, 1996; Rice et al., 1995; Rice, Wexler, \& Hershberger, 1998; Rice, Wexler, \& Redmond, 1999). The typical error pattern is for children with SLI to omit these morphemes more frequently and for a longer time period than control children. Children with SLI rarely show overt error patterns such as misusing finiteness morphemes in inappropriate contexts. That is, children with SLI may err by saying "She walk to school yesterday," instead of "She walked to school yesterday," but they avoid "I walks to school" for "I walk to school." During this same time period, children with SLI also avoid omissions or overt errors on nonfiniteness morphemes, such as plural $-s$ or progressive -ing; these morphemes have already been mastered. In children with SLI, the finiteness related morphemes all follow a similar growth trajectory (Rice et al., 1998), and use of these morphemes can serve as a clinical marker for SLI (Rice \& Wexler, 2001). 


\section{Pragmatics}

A final linguistic domain that is often studied in developmental language disorders is pragmatics. In a general sense, pragmatics refers to the ability to use language for social communication in a manner that allows the listener to clearly and accurately interpret the speaker's references and intentions. Specific aspects of pragmatics include discourse maintenance, use of a range of speech acts, and narrative abilities. Overall, children with SLI tend to have mild pragmatic difficulties (Craig \& Evans, 1993; Hadley \& Rice, 1991). In a study investigating the relative strengths and weaknesses of children with SLI, 85\% displayed a profile with relatively higher scores in social communication than semantic/syntactic performance (Tomblin, Zhang, Catts, Ellis Weismer, \& Weiss, 2004). This result suggests that any pragmatic difficulties in children with SLI are secondary to primary deficits in semantics and syntax, although this interpretation is controversial and remains a matter of ongoing investigation.

\section{Delay versus deviance/disruption}

By definition, children with SLI perform below age-matched controls on language measures; another useful group comparison is between children with SLI and younger children matched for language abilities. That is, one can ask whether children with SLI display a pattern of language growth similar to that seen in younger children with typical language development. A similar pattern of growth would indicate a delayed linguistic system, whereas a growth pattern that differs from typical development would indicate a deviant linguistic system. Distinguishing between a delayed and deviant linguistic system has important implications for understanding the mechanisms that underlie specific language deficiencies as well as implications for appropriate intervention approaches and prognosis.

In general, children with SLI show a delayed pattern of linguistic growth with some aspects of deviant growth (cf. Leonard, 1998). Recent documentation of longitudinal growth of morphosyntactic development provides a clear example of how this distinction plays out in the linguistic systems of affected children. Throughout the preschool and early school-aged years, the percentage of obligatory use of grammatical tense and agreement markers for children with SLI is below that of age-matched controls and language-matched controls (Rice, 2003, 2004a, 2004b; Rice \& Wexler, 1996; Rice et al., 1995, 1998, 1999). The growth curves show a delayed onset in this linguistic dimension, even relative to younger language-matched children. This is in contrast to the dimension of vocabulary development, where the affected children are similar to the younger children (cf. Rice, 2003, 2004a, 2004b). For years this pattern persists, that is, vocabulary acquisition tracks with the younger children, but the grammar marker trails behind. In this way, the two systems are never as fully synchronized as in typical linguistic development, hence the deviant nature of the grammatical marker. Rice has referred to this phenomenon as "delay within a delay" (2003) or "delay with disruption" (2004a, 2004b). Further indication of deviance is observed at middle childhood, when it seems that the affected children do not fully resolve the 
Rice et al.: Language symptoms of developmental language disorders

earlier grammatical limitations. At 8 years of age, the younger children perform near ceiling level whereas the children with SLI still make errors in recognizing tense and agreement omissions in a grammaticality judgment task of $w h$ - and yes/no questions (Rice, 2004a, 2004b). These differences suggest that children with SLI might not catch up to their peers in terms of morphosyntactic development, causing a long-standing weakness or disruption of a fundamental property of clause structure.

Rice $(2003,2004 a, 2004 b)$ argues that the overall picture of language growth in SLI reveals underlying robust developmental and timing mechanisms that are common to children with SLI and unaffected children, but differentiated by an offset in onset timing for the affected children, which manifests as an overall delay. Further, this pattern of delayed onset is even more pronounced for the grammatical marker in the domain of morphosyntax, where this element is out of sync for a protracted period, even though the timing and growth mechanisms parallel those of younger children. Rice further proposes that consideration of growth and timing mechanisms, across multiple dimensions of language, may prove fruitful as a way of unifying observations across different forms of language disorders in different clinical conditions, and as a way of linking surface linguistic symptoms to underlying neurocognitive and genetic factors.

\section{Language and cognition}

The general issue of the relationship between language and nonverbal cognitive skills has also been of great interest to investigators of SLI. By definition, children with SLI do not have congruent language and nonverbal cognitive abilities because language performance must be below age expectations whereas nonverbal cognition must be at or above age expectations (Stark \& Tallal, 1981). Some researchers have suggested that the definition of SLI be revised by eliminating the requirement of normal nonverbal intelligence (Cole, Dale, \& Mills, 1990; Lahey, 1990; Plante, 1998). However, recent work has shown that to an important extent the domains of cognition and language can operate as orthogonal dimensions, at least in the area of morphological development. In an epidemiologically ascertained group of kindergarten children, four groups were identified: children in normal range or above on both language and nonverbal IQ test, children with SLI, children with nonspecific language impairment (NLI; i.e., below normal in both language and nonverbal cognitive skills), and children described as low cognition (LC; i.e., language in normal range and nonverbal IQ performance below normal). The LC group performed as well as the normal group on the grammatical marker tasks, indicating that a low cognitive level did not necessitate low levels of grammatical tense marking; the NLI group performed below the SLI group, indicating that if both dimensions are affected, then the performance on the grammar marker is additively affected (Rice et al., 2004; Tomblin et al., 1997). These findings are consistent with other studies that found no relationship of nonverbal IQ and performance of the grammatical marker (Conti-Ramsden, Botting, \& Faragher, 2001; Rice et al., 1998; Rice, Wexler, Marquis, \& Hershberger, 2000). 


\section{AUTISM SPECTRUM DISORDERS}

Autism is a developmental disorder that is diagnosed based on the presence of deficits in three areas, communication, social interaction, and repetitive and stereotyped behaviors, interests, and activities (American Psychiatric Association, 1994). The "autism spectrum" refers to the existence of substantial subgroups of individuals who share some core characteristics of autism but still differ in important ways. These subgroups include Asperger syndrome (which appears to be primarily a social disorder), pervasive developmental disorder (which is diagnosed as a mild social or communication disorder), autism with severe mental retardation (these individuals are generally nonverbal), and autism with fragile $\mathrm{X}$ syndrome (these individuals typically have severe mental retardation).

Although communication deficits are part of the diagnostic criteria for autism, children with autism vary widely in their communication skills, with some nonverbal and others having adequate skills to participate in conversation. Previous studies have suggested that up to $50 \%$ of children with autism were nonverbal (Lord \& Rutter, 1994), however, more recent studies indicate the percentage may be much lower. Using the ADOS and ADI-R to measure communication skills, Lord, Risi, and Pickles (2004) found that at 9 years old, only 14-20\% of children with autism could be labeled as nonverbal, with nonverbal being defined as the daily use of five or fewer words. The subset of children with autism who are nonverbal can be described as having a deviant pattern of language development because the lack of verbal communication skills clearly differentiates these children from typically developing children at all but the youngest ages. Lord et al. (2004, p. 13) note that the language skills of these children are so limited "that [it] cannot be judged in terms of abnormalities." This observation further supports the notion that nonverbal children with autism have a deviant language system. However, the children with autism who do use verbal communication can be described more in terms of a language delay than deviance. Tager-Flusberg (2004) suggests that a subgroup of these verbal children have a language delay similar to SLI.

Because autism is defined in terms of both language delays and global developmental delays, the comparison between language and nonverbal cognitive skills is not as straightforward as it is for children with SLI. Findings by Joseph, Tager-Flusberg, and Lord (2002) suggest that the congruence between language and nonverbal intelligence may change over time. They found that more preschool children with autism had verbal scores below nonverbal scores, compared to school-age children. Further support for a discrepancy between verbal and nonverbal skills at early ages is the finding that at the first-word stage, children with autism have higher nonverbal skills than children with other disorders when they begin using single words (Lord et al., 2004). The congruence between verbal and nonverbal skills may be affected by whether the child is verbal or nonverbal. For nonverbal children with autism, only $16 \%$ showed a discrepancy between verbal and nonverbal cognitive skills (Lord et al., 2004), suggesting that for a majority, their linguistic delays were to be expected based on nonverbal cognitive performance. However, Tager-Flusberg (2004) found that most verbal children with autism had normal nonverbal intelligence. Therefore, at least for young children 
Rice et al.: Language symptoms of developmental language disorders

with autism and older, verbal children with autism, there is a discrepancy between language and nonverbal cognitive skills.

Verbal and nonverbal children with autism also differ in terms of speech abilities; speech is spared in children with verbal language (Kjelgaard \& Tager-Flusberg, 2000) but not in those without verbal language. Studies have found that verbal children with autism were never classified as having expressive phonology disorders (Allen, 1989; Rapin, 1996). Additionally, for performance on the GoldmanFristoe Test of Articulation (GFTA), the mean standard score for children with autism was approximately 90 (with a mean of 100) for children ages 4-14. Scores on the GFTA were not affected by whether the child had a language impairment; that is, children with and without language impairment performed within the normal range (Tager-Flusberg, 2004). These results are similar to those for children with SLI, with language impairment not being a factor in the presence of speech impairment.

As compared to SLI, more is known about the early lexical development of children with autism. The main reason for this difference in understanding of lexical growth is the time of diagnosis. For children with autism, delayed language acquisition is the primary referral concern (Siegal, Pliner, Eschler, \& Elliott, 1988). Perhaps the most interesting and unexpected finding concerning early lexical development of children with autism is a subgroup of children who show use of early words followed by a decline in the use of these words. Lord et al. (2004) found that $20 \%$ of children with autism showed a period of such language loss. At around 1 year old, these children used at least three words for at least 1 month, followed by a period of no words for at least 1 month. Then these children regained their earlier words at about the same age as other children with autism who had a general delayed onset of first words. These two patterns of early lexical growth once again show the heterogeneity of children with autism; the language loss group differs from what is known about other developmental language disorders and displays a deviant type of lexical growth, whereas the majority of children show a delayed onset of first words similar to that seen in other disorders.

Recent studies conducted by Tager-Flusberg and colleagues (Condouris, Evancie, \& Tager-Flusberg, 2002; Roberts, Rice, \& Tager-Flusberg, 2005) investigated the morphosyntactic abilities of children with autism using experimental tasks similar to those used in studies of children with SLI. Because these tasks require sentence-level responses, participants are constrained to verbal children with autism. A further distinction made within the group of children with autism is between children with and without language impairment. Allen and Rapin (1980, 1992) found that $67 \%$ of kids with autism had mixed expressive/receptive language delay; that is, within the group of verbal children with autism, some have language impairment and some do not. On morphosyntactic tasks eliciting past tense and third person singular verbs, the children with autism and language impairment performed poorer than the children with autism and no language impairment, with the children without language impairment producing twice as many correct answers (Roberts, Rice, \& Tager-Flusberg, 2000). Similarly to children with SLI, the most common error type was omission of the finiteness marker. A corresponding study of morphosyntactic abilities in spontaneous speech found that children with autism and language impairment differed from the children without language 
Rice et al.: Language symptoms of developmental language disorders

impairment, but only for third person singular $-s$. All children produced the other finiteness morphemes correctly over $90 \%$ of the time. These results show that, like children with SLI, children with autism and language impairment have difficulty with morphosyntax, specifically finiteness marking.

In contrast to children with SLI, pragmatic impairments are not a secondary result of language impairment, but rather pragmatic deficits are a defining feature of autism. It is widely agreed upon that pragmatic impairments are the unifying feature among all children with autism (Lord \& Paul, 1997; Tager-Flusberg, 1999). Despite the heterogeneity of this population, such as the inclusion of both verbal and nonverbal children and the presence or absence of a linguistic disorder, all children will show pragmatic impairments. These pragmatic deficits include: restricted range of speech acts (Loveland, Landry, Hughes, Hall, \& McEvoy, 1988; Wetherby, 1986); conversational and narrative deficits (Loveland \& Tunali, 1993; Tager-Flusberg \& Anderson, 1991; Tager-Flusberg \& Sullivan, 1995); and an inability to consider the listener's perspective (Paul \& Cohen, 1984). These skills are impaired in children with autism but result from the underlying autistic deficit; that is, pragmatics are impaired across all people with autism and do not determine whether a child will have concomitant language problems.

\section{FRAGILE X SYNDROME}

Fragile $\mathrm{X}$ syndrome is the most common form of inherited mental retardation and results from a mutation on the FMRl gene at Xq27.3. Because this mutation occurs on the $\mathrm{X}$ chromosome and females have two $\mathrm{X}$ chromosomes, only one of which is affected, males are more likely to be more severely affected than females (Hagerman, 1999; Keysor \& Mazzocco, 2002). The characteristics of fragile X syndrome include macroorshidism, an elongated face, large ears, a prominent jaw, increased head circumference, and mitral valve prolapse (Hagerman, 2002). Interestingly, there is a comordibity with autism of up to $35 \%$ (Bailey, Hatton, \& Skinner, 1998; Bailey et al., 1998; Feinstein \& Reiss, 2001; Rogers, Wehner, \& Hagerman, 2001). Fragile $\mathrm{X}$ is presently the only known genetic cause of autism. Furthermore, these are usually individuals with severe mental retardation as well (Bailey, Hatton, \& Skinner, 2001).

In terms of language development, fragile $\mathrm{X}$ syndrome is the least understood developmental language disorder discussed here. One fact that is known, and that differs from other disorders such as SLI, is that children with fragile X syndrome have delayed language development but that this delay tends to be congruent with nonverbal cognitive delays (Abbeduto \& Murphy, 2004). Roberts, Mirrett, and Burchinal (2001) prospectively studied the receptive and expressive language skills of 39 young males with fragile X, 20-86 months of age, and found that the participants acquired expressive language skills more slowly (i.e., at one third the rate expected for typically developing children) than they did receptive skills (i.e., at one-half the rate expected for typically developing children) over time. They also reported that the subset of boys with fragile $X$ and autism in their sample were either completely nonverbal or minimally verbal. Similarly to children with Williams syndrome, children with fragile $X$ have a relative strength in verbal abilities compared to visual-spatial cognitive tasks (Bailey et al., 2004). 
Rice et al.: Language symptoms of developmental language disorders

In contrast to most of the other language disorders described here, children with fragile X syndrome have speech problems. These deficits include a harsh vocal quality, rapid and variable rate of speech, and persistent articulation difficulties (Abbeduto \& Hagerman, 1997; Hagerman, 1999). These speech difficulties combine to make speech relatively unintelligible (Paul et al., 1987; Spinelli, Rocha, Giacheti, \& Richieri-Costa, 1995). One factor that may play an important role in decreased speech intelligibility is the common finding among young boys with fragile $\mathrm{X}$ of generalized hypotonia that also involves oral-facial musculature (Hagerman, 1996). Many males also evidence speech disfluencies that appear to increase with increased anxiety (Newell, Sanborn, \& Hagerman, 1983). Therefore, children with fragile $\mathrm{X}$ syndrome have both delayed speech and language abilities, with language delays congruent with nonverbal cognitive delays.

The pragmatic abilities of children with fragile $\mathrm{X}$ syndrome were investigated with the same experimental barrier task as used in studies of children with Down syndrome (Abbeduto \& Murphy, 2004). Strengths of the children with fragile $\mathrm{X}$ syndrome included appropriate switching from indefinite to definite object descriptions during the conversation and the use of referential frames. These children did not perform as well as mental age-matched controls on the use of unique object mappings, the use of consistent descriptions for recurring shapes, and the signaling of comprehension to the other communication partner. Children with fragile $\mathrm{X}$ syndrome have also been shown to have a delayed theory of mind (Garner, Callias, \& Turk, 1999); however, Abbeduto and Murphy (2004) found that they performed similarly to mental-age matched controls on theory of mind questions.

\section{WILLIAMS SYNDROME}

Williams syndrome is a genetic disorder caused by a microdeletion on the long arm of chromosome 7q11.23. This genetic disruption results in dysmorphic facial features, a hoarse voice quality, heart valve problems, kidney problems, hypersensitivity to sound, joint abnormalities, an overfriendly personality, and mild to moderate mental retardation. In terms of language abilities, children with Williams syndrome show a delay in language development but do not show a precocious skill level as previous research may have suggested. Some researchers believe that these children have deviant language development in that they rely on rote auditory memory rather than underlying grammatical skills for language production (Karmiloff \& Karmiloff-Smith, 2001; Karmiloff-Smith, 1997). Zukowski (2004) recently suggested that children with Williams syndrome do not have deviant language systems. Zukowski elicited production of sentences containing relative clauses and negative questions. The children with Williams syndrome made errors that were developmental in nature; that is, typically developing children made the same errors at early ages. The developmental nature of these errors suggest a delayed rather than deviant pattern of linguistic development. However, the evidence suggests that even adults with Williams syndrome make errors on these grammatical structures, suggesting that the end point of development may be deviant. 
Rice et al.: Language symptoms of developmental language disorders

Children with Williams syndrome show a pattern of language versus nonverbal cognitive abilities that contrasts with that of children with SLI. In both disorders, there is a discrepancy between language and nonverbal cognitive skills. Children with SLI show an incongruence with nonverbal skills greater than language skills whereas children with Williams syndrome have language skills greater than nonverbal skills. This discrepancy is especially true for nonverbal spatial skills, which are severely impaired in children with Williams syndrome (Landau \& Zukowski, in press). Additionally, toddlers with Williams syndrome pass more language items than nonlanguage items on the Bayley (Mervis, 2004). These findings show a distinct pattern of noncongruence for children with Williams syndrome with language skills exceeding nonverbal skills.

Little data exists on the speech development of children with Williams syndrome. Although a hoarse vocal quality is part of the syndrome profile, this deficiency would not be expected to interfere with overall intelligibility.

Similarly to children with SLI and autism, children with Williams syndrome have delayed first words and word combinations as compared to typically developing children (Mervis, Robinson, Rowe, Becerra, \& Klein-Tasman, in press). However, children with Williams syndrome differ from children with other developmental language disorders because their vocabulary abilities, and their overall language skills, exceed their cognitive levels (Bellugi, Bihrle, Neville, Doherty, \& Jernigan, 1992). In contrast, children with other developmental disorders must reach higher cognitive levels before acquiring their first words than would be expected based on typical development. Therefore, children with Williams syndrome are delayed in acquiring their first words and word combinations.

Children with Williams syndrome differ from children with SLI and autism in terms of their morphosyntactic abilities. In general, children with Williams syndrome have delayed acquisition of grammatical morphology; however, morphological development occurs at a normal pace after onset (Mervis et al., 1995) and by adolescence these children are at ceiling levels of correct use of grammatical morphemes in obligatory contexts (Clahsen \& Almazan, 1998). In a study of the elicited production of finiteness morphemes, children with Williams syndrome were near ceiling at 7 years old, a level of performance that exceeded both the language-matched controls and children with SLI (Rice, 2003; Rice, Mervis, Klein, \& Rice, 1999). Combining the findings for lexical and morphological development, a unique pattern of acquisition emerges for children with Williams syndrome; these children may show a delayed onset of these skills, but reach expected levels of growth despite persistent delays in nonverbal cognitive skills.

Zukowski (2004) conducted two studies to investigate more complex linguistic skills of children with Williams syndrome. The experimental tasks used elicited complex sentences containing relative clauses or questions. Zukowski was interested in studying relative clauses because children with Williams syndrome are known to have difficulty comprehending relative clauses (Karmiloff-Smith et al., 1997; Mervis, Morris, Bertrand, \& Robinson, 1999; Volterra, Capirci, Pezzini, Sabbadini, \& Vicari, 1996), but the reason for this deficit was unknown. Children with Williams syndrome, ages 10-16, and language-matched controls, ages 4-7, participated in the relative clause experiment. Children were asked to identify characters in a way that elicited target structures such as "the girl who's pointing 
Rice et al.: Language symptoms of developmental language disorders

at the cow" (regarded as a "subject gap" construction) and "the man who the girl is jumping over" (an "object gap" construction). All of the children in both groups produced subject and object gap relative clauses and $95 \%$ of the responses for both groups were grammatical. However, not all of these grammatical responses were semantically correct; that is, not all accurately described the targeted scene. The most common error type for both the affected and unaffected children was a mapping error in which an object or person was incorrectly described. In the question elicitation study, the children with Williams syndrome were 8-16 years old and the language-matched controls were 4-7 years old. Like the relative clauses study, both groups performed at similar accuracy levels and produced similar types of errors. The children were $90 \%$ accurate in producing affirmative questions but only $49 \%$ accurate for negative questions. The most common error type involved a lack of negation movement, such as "where your dogs can't sleep?" The results of these two studies show that children with Williams syndrome show developmentally appropriate error types for complex grammatical structures.

The pragmatic skills of children with Williams syndrome have not been widely investigated, although the presence of an overly friendly personality suggests that social communication is not a weakness for these children.

\section{DOWN SYNDROME}

Down syndrome is the most common genetic (although noninherited) cause of mental retardation. It is most often caused by a trisomy of chromosome 21 . This genetic abnormality results in a distinct facial appearance, heart and respiratory problems, and mental retardation with IQs between 35 and 70 (Chapman \& Hesketh, 2000).

One of the affects of Down syndrome is a disordered language system with vocabulary skills less impaired than grammatical abilities (Miller, 1996). In comparison to nonverbal cognitive skills, these children show an incongruence with language performance, such that they have a slower acquisition of overall language than expected for the level of nonlinguistic development (Chapman \& Hesketh, 2000). However, this discrepancy between linguistic and nonlinguistic skills differs for different domains of language. Vocabulary skills are often at or above nonverbal levels but syntactic development is at lower levels than nonverbal abilities (Chapman, Schwartz, \& Kay-Raining Bird, 1991). Therefore, children with Down syndrome show an incongruence between nonverbal cognition and grammatical development but a congruence between vocabulary and nonverbal cognitive skills.

The use of finiteness marking has not been as widely studied in children with Down syndrome as it has in other types of language disorders, although a few studies are available. Eadie, Fey, Douglas, and Parsons (2002) compared the accuracy of finiteness marking in the spontaneous speech of children with Down syndrome and children with SLI. These two groups of children performed similarly, as would be expected if children with Down syndrome have a delayed syntactic development. However, an unexpected finding of the study was that the accuracy of use of finiteness markers did not differ from the use of control morphemes that do not mark finiteness (e.g., plural $-s$ ). The lack of a difference between the 
Rice et al.: Language symptoms of developmental language disorders

experimental and control morphemes for children with SLI is surprising given the previous research and warrants further investigation. However, this study suggests that children with Down syndrome may display a similar pattern of delayed acquisition of finiteness as children with SLI. Laws and Bishop (2003) compared the performance of adolescents with Down syndrome and children with SLI matched for nonverbal cognitive ability. They reported similarities such that vocabulary was an area of relative strength for both groups, whereas syntax was poor. On elicitation tasks, both groups showed deficits in the production of grammatical markers of verb tense, providing further indication of similarities in difficulties with the grammatical marker.

Unlike the other developmental language disorders discussed, children with Down syndrome have significant speech problems (Chapman \& Hesketh, 2000; Kumin, 1996). In spontaneous speech, children with Down syndrome are more unintelligible than control children (Abbeduto \& Murphy, 2004). These speech difficulties are due to anatomical differences in the vocal tract and periodic hearing loss due to frequent otitis media. Therefore, unlike children with many other developmental language disorders, children with Down syndrome have speech deficits in addition to cognitive and language delays.

Abbeduto and Murphy (2004) investigated the pragmatic abilities of children with Down syndrome, specifically discourse abilities, using a barrier task. Results indicate both strengths and weaknesses in the children's ability to communicate with a naïve speaker. Areas in which the children with Down syndrome performed similarly to control children included appropriate switching from indefinite to definite object descriptions over time and the use of consistent object descriptions for recurring shapes. The children with Down syndrome did not perform as well as control children in terms of the use of unique mappings for objects, the use of referential frames, and the signaling of comprehension to the other speaker. This pattern of results suggests that children with Down syndrome are not as robust at accounting for the informational needs of their listener but do understand the increase in shared knowledge that occurs during the course of a conversation. In a related pragmatic task examining children's theory of mind, children with Down syndrome perform poorer than control children (Abbeduto \& Murphy, 2004; Garner et al., 1999). Thus, the pragmatic abilities of children with Down syndrome are impaired, with some areas of strength.

\section{CONCLUSIONS}

Available evidence suggests some preliminary conclusions. Across the different dimensions of language, there are clearly relative areas of strengths and weaknesses across the various clinical conditions, suggesting that the dimensions of speech, vocabulary/semantics, grammar/syntax, and pragmatics warrant differentiation in descriptions of symptoms of language disorders. Although available studies provide pieces of the full set of comparisons and contrast, there is a great need for systematic comparisons of dimensions across disorders, at greater levels of specificity than is currently available.

The contrast between delayed versus deviant aspects of language acquisition shows considerable promise in providing an overarching perspective on the ways 
Rice et al.: Language symptoms of developmental language disorders

in which language impairments can be manifest. Even at this relatively early stage of inquiry, it is clear that this contrast plays out differently across different dimensions of language, is most clearly revealed in longitudinal growth data, and hints at relative strengths and weaknesses across clinical conditions. It is possible that delayed onset is a hallmark characteristic across most of the known clinical forms of language impairments (Rice, 2003, 2004a, 2004b). Acquisition of lexical vocabulary seems to generally follow a delay pattern, with the possible fascinating exception of vocabulary loss in children with autism. Morphosyntax shows a pattern of disruption in children with SLI and children with Down syndrome and relative strength in children with Williams syndrome. Such comparisons, although at the beginning stages of inquiry, point toward underlying timing mechanisms at work that need to be better understood and are plausibly connected to underlying neurocognitive and genetic factors.

Finally, it has long been recognized that the study of individuals with language impairments provides a valuable entry point into the complexities of the relationship between language and cognition and the extent to which the two dimensions of children's development are unique or shared. The other papers in this Special Issue point to the multiple research challenges inherent in sorting out this fundamental question, across the different dimensions of language. Advances in genetics and neurocognitive measurement promise new avenues of inquiry. At the same time, the need for careful linguistic description is as urgent as ever, for the dual purposes of scientific inquiry and clinical application.

\section{ACKNOWLEDGMENTS}

Preparation of this paper was supported by the Merrill Advanced Studies Center and NIH awards P30 HD002528 (PI) to Steve Warren; and P30 DC005803 (PI), DC0180, and DC005226 to Mabel Rice.

\section{REFERENCES}

Abbeduto, L., \& Hagerman, R. (1997). Language and communication in fragile X syndrome. Mental Retardation and Developmental Disabilities Research Reviews, 7, 45-55.

Abbeduto, L., \& Murphy, M. M. (2004). Language, social cognition, maladaptive behavior, and communication in Down syndrome and fragile X syndrome. In M. L. Rice \& S. F. Warren (Eds.), Developmental language disorders: From phenotypes to etiologies. Mahwah, NJ: Erlbaum.

Allen, D. (1989). Developmental language disorders in preschool children: Clinical subtypes and syndromes. School Psychology Review, 18, 442-451.

Allen, D., \& Rapin, I. (1980). Language disorders in preschool children: Predictors of outcome. A preliminary report. Brain and Development, 2, 73-80.

Allen, D., \& Rapin, I. (1992). Autistic children are also dysphasic. In H. Naruse \& E. Ornitz (Eds.), Neurobiology of infantile autism (pp. 73-80). Amsterdam: Excerpta Medica.

American Psychiatric Association. (1994). Diagnostic and statistical manual of mental disorders (4th ed.). Washington, DC: Author.

Bailey, D. B., Hatton, D. D., \& Skinner, M. (2001). Autistic behavior, FMR1 protein, and developmental trajectories in young males with fragile X syndrome. Journal of Autism and Developmental Disorders, 31, 165-174.

Bailey, D. B., Mesibov, G. B., Hatton, D. D., Clark, R. D., Roberts, J. E., \& Mayhew, L. (1998). Autistic behavior in young boys with fragile $\mathrm{X}$ syndrome. Journal of Autism and Developmental Disorders, 28, 499-508. 
Rice et al.: Language symptoms of developmental language disorders

Bailey, Jr., D. B., Hatton, D. D., \& Skinner, M. (1998). Early developmental trajectories of males with fragile X syndrome. American Journal on Mental Retardation, 103, 29-39.

Bailey, Jr., D. B., Roberts, J. E., Hooper, S. R., Hatton, D. D., Mirrett, P. L., Roberts, J. E., \& Schaaf, J. M. (2004). Research on fragile X syndrome and autism: Implications for the study of genes, environments, and developmental language disorders. In M. L. Rice \& S. F. Warren (Eds.), Developmental language disorders: From phenotypes to etiologies. Mahwah, NJ: Erlbaum.

Bellugi, U., Bihrle, A., Neville, H., Doherty, S., \& Jernigan, T. L. (1992). Language, cognition, and brain organization in a neurodevelopmental disorder. In M. Gunnar \& C. Nelson (Eds.), Developmental behavioral neuroscience: The Minnesota Symposia on Child Psychology. Hillsdale, NJ: Erlbaum.

Chapman, R. S., \& Hesketh, L. J. (2000). Behavioral phenotype of individuals with Down syndrome. Mental Retardation and Developmental Disabilities Research Reviews, 6, 84-95.

Chapman, R. S., Schwartz, S. E., \& Kay-Raining Bird, E. (1991). Language skills of children and adolescents with Down syndrome; I. Comprehension. Journal of Speech and Hearing Research, $34,1106-1120$.

Clahsen, H., \& Almazan, M. (1998). Syntax and morphology in Williams syndrome. Cognition, 68, 167-198.

Cole, K. N., Dale, P. S., \& Mills, P. E. (1990). Defining language delay in young children by cognitive referencing: Are we saying more than we know? Applied Psycholinguistics, 11, 291-302.

Condouris, K., Evancie, L., \& Tager-Flusberg, H. (2002, November). Tense error patterns in children with autism and children with SLI. Paper presented at the International Meeting for Autism Research, Orlando, FL.

Conti-Ramsden, G., Botting, N., \& Faragher, B. (2001). Psycholinguistic markers for specific language impairment (SLI). Journal of Child Psychology and Psychiatry, 42, 741-748.

Craig, H., \& Evans, J. (1993). Pragmatics and SLI: Within-group variations in discourse behaviors. Journal of Speech, Language, and Hearing Research, 42, 1195-1204.

Eadie, P. A., Fey, M. E., Douglas, J. M., \& Parsons, C. L. (2002). Profiles of grammatical morphology and sentence imitation in children with specific language impairment and Down syndrome. Journal of Speech, Language, and Hearing Research, 45, 720-732.

Feinstein, C., \& Reiss, A. L. (2001). Autism: The point of view from fragile X studies. Journal of Autism and Developmental Disorders, 28, 393-405.

Fisher, S. E. (2005). Dissection of molecular mechanisms underlying speech and language disorders. Applied Psycholinguistics, 26, 111-128.

Garner, C., Callias, M., \& Turk, J. (1999). Executive function and theory of mind performance of boys with fragile-X syndrome. Journal of Intellectual Disability Research, 43, 466-474.

Guasti, M. T. (2002). Language acquisition: The growth of grammar. Cambridge, MA: MIT Press.

Hadley, P. A., \& Rice, M. L. (1991). Conversational responsiveness of speech and language impaired preschoolers. Journal of Speech and Hearing Research, 34, 1308-1317.

Hagerman, R. J. (1996). Physical and behavioral phenotype. In R. J. Hagerman \& A. Cronister (Eds.), Fragile X syndrome: Diagnosis, treatment, and research (2nd ed., pp. 3-87). Baltimore, MD: Johns Hopkins University Press.

Hagerman, R. J. (1999). Fragile X syndrome. In R. J. Hagerman (Ed.), Neurodevelopmental disorders. Oxford: Oxford University Press.

Hagerman, R. (2002). The physical and behavioral phenotype. In R. J. Hagerman \& P. J. Hagerman (Eds.), Fragile X syndrome: Diagnosis, treatment, and research (3rd ed., pp. 1-109). Baltimore, MD: Johns Hopkins University Press.

Joseph, R. M., Tager-Flusberg, H., \& Lord, C. (2002). Cognitive profiles and social-communicative functioning in children with autism spectrum disorder. Journal of Child Psychology and Psychiatry and Allied Disciplines, 43, 807-821.

Karmiloff, K., \& Karmiloff-Smith, A. (2001). Pathways to language. Cambridge, MA: Harvard University Press.

Karmiloff-Smith, A. (1997). Crucial differences between developmental cognitive neuroscience and adult neuropsychology. Developmental Neuropsychology, 13, 513-524.

Karmiloff-Smith, A., Grant, J., Berthoud, I., Davies, M., Howlin, P., \& Udwin, O. (1997). Language and Williams syndrome: How intact is "intact"? Child Development, 68, 246-262.

Keysor, C., \& Mazzocco, M. M. (2002). A developmental approach to understanding fragile X syndrome in females. Microscopy Research and Technique, 57, 179-186. 
Rice et al.: Language symptoms of developmental language disorders

Kjelgaard, M., \& Tager-Flusberg, H. (2000). An investigation of language profiles in autism: Implications for genetic subgroups. Language and Cognitive Processes, 15, 1-22.

Kumin, L. (1996). Speech and language skills in children with Down syndrome. Mental Retardation and Developmental Disabilities Research Reviews, 2, 109-115.

Lahey, M. (1990). Who shall be called language disordered? Some reflections and one perspective. Journal of Speech and Hearing Disorders, 55, 612-620.

Landau, B., \& Zukowski, A. (in press). Objects, notions, and paths: Spatial language in children with Williams syndrome. Developmental Neuropsychology.

Laws, G., \& Bishop, D.V.M. (2003). A comparison of language abilities in adolescents with Down syndrome and children with specific language impairment. Journal of Speech, Language, and Hearing Research, 46, 1324-1339.

Leonard, L. B. (1998). Children with specific language impairment. Cambridge, MA: MIT Press.

Levy, Y., \& Schaeffer, J. (Eds.). (2003). Language competence across populations: Toward a definition of specific language impairment. Mahwah, NJ: Erlbaum.

Lord, C., \& Paul, R. (1997). Language and communication in autism. In D. J. Cohen \& F. R. Volkmar (Eds.), Handbook of autism and pervasive development disorders (2nd ed.). New York: Wiley.

Lord, C., Risi, S., \& Pickles, A. (2004). Trajectory of language development in autistic spectrum disorders. In M. L. Rice \& S. F. Warren (Eds.), Developmental language disorders: From phenotypes to etiologies. Mahwah, NJ: Erlbaum.

Lord, C., \& Rutter, M. (1994). Autism and pervasive development disorders. In E. Taylor (Ed.), Child and adolescent psychiatry: Modern approaches (Vol. 3, pp. 569-593). Oxford: Blackwell.

Loveland, K., Landry, S., Hughes, S., Hall, S., \& McEvoy, R. (1988). Speech acts and the pragmatic deficits of autism. Journal of Speech and Hearing Research, 31, 593-604.

Loveland, K., \& Tunali, B. (1993). Narrative language in autism and the theory of mind hypothesis: A wider perspective. In S. Baron-Cohen, H. Tager-Flusberg, \& D. J. Cohen (Eds.), Understanding other minds: Perspectives from autism. Oxford: Oxford University Press.

Mervis, C. B. (2004). Cross-etiology comparisons of cognitive and language development. In M. L. Rice \& S. F. Warren (Eds.), Developmental language disorders: From phenotypes to etiologies. Mahwah, NJ: Erlbaum.

Mervis, C. B., Bertrand, J., Robinson, B. F., Armstrong, S. C., Klein, B. P., \& Turner, N. D. (1995). Early language development of children with Williams syndrome. Paper presented at the Biennial Meeting of the Society for Research in Child Development, Indianapolis, IN.

Mervis, C. B., Morris, C. A., Bertrand, J., \& Robinson, B. D. (1999). Williams syndrome: Findings from an integrated program of research. In H. Tager-Flusberg (Ed.), Neurodevelopmental disorders: Contributions to a new framework from the cognitive neurosciences. Cambridge, MA: MIT Press.

Mervis, C. B., Robinson, B. F., Rowe, M. L., Becerra, A. M., \& Klein-Tasman, B. P. (in press). Language abilities of people with Williams syndrome. In L. Abbeduto (Ed.), International review of research in mental retardation (Vol. 27). Orlando, FL: Academic Press.

Miller, J. (1996). The search for the phenotype of disordered language performance. In M. L. Rice (Ed.), Toward a genetics of language (pp. 297-314). Mahwah, NJ: Erlbaum.

Morris, C. A. (2004). Genotype phenotype correlations: Lessons from Williams syndrome research. In M. L. Rice \& S. F. Warren (Eds.), Developmental language disorders: From phenotypes to etiologies. Mahwah, NJ: Erlbaum.

Müller, R. A. (2004). Genes, language disorders, and developmental archaeology: What role can neuroimaging play? In M. L. Rice \& S. F. Warren (Eds.), Developmental language disorders: From phenotypes to etiologies. Mahwah, NJ: Erlbaum.

Müller, R.-A. (2005). Neurocognitive studies of language impairments: The bottom-up approach. Applied Psycholinguistics, 26, 65-78.

Newell, K., Sanborn, B., \& Hagerman, R. J. (1983). Speech and language dysfunction in fragile X syndrome. In R. J. Hagerman \& P. M. McBogg (Eds.), The fragile X syndrome: Diagnosis, biochemistry, and intervention (pp. 175-200). Dillon, CO: Spectra.

Paul, R. (1996). Clinical implication of the natural history of slow expressive language development. American Journal of Speech-Language Pathology, 5, 5-21.

Paul, R., \& Cohen, D. J. (1984). Responses to contingent queries in adults with mental retardation and pervasive developmental disorders. Applied Psycholinguistics, 5, 349-357. 
Rice et al.: Language symptoms of developmental language disorders

Paul, R., Dykens, E., Leckman, J. F., Watson, M., Bregman, W. R., \& Cohen, D. J. (1987). A comparison of language characteristics of mentally retarded adults with fragile $\mathrm{X}$ syndrome and those with nonspecific mental retardation and autism. Journal of Autism and Developmental Disorders, $17,457-468$.

Phillips, C. (2004). Linguistics and linking problems. In M. L. Rice \& S. F. Warren (Eds.), Developmental language disorders: From phenotypes to etiologies. Mahwah, NJ: Erlbaum.

Phillips, C. (2005). Electrophysiology in the study of developmental language impairments: Prospects and challenges for a top-down approach. Applied Psycholinguistics, 26, 7996.

Plante, E. (1998). Criteria for SLI: The Stark and Tallal legacy and beyond. Journal of Speech, Language, and Hearing Research, 41, 951-957.

Rapin, I. (Ed.). (1996). Preschool children with inadequate communication (Clinics in developmental medicine, No. 139). London: Mac Keith Press.

Rescorla, L. (2002). Language and reading outcomes to age 9 in late-talking toddlers. Journal of Speech, Language, and Hearing Research, 45, 360-371.

Rescorla, L. (2003). Outcome for toddlers with specific expressive language delay (SELD) at ages 3, 4, 5, 6, 7, \& 8. Society for Research in Child Development Abstracts, 9, 566.

Rice, M. L. (2003). A unified model of specific and general language delay: Grammatical tense as a clinical marker of unexpected variation. In Y. Levy \& J. Schaeffer (Eds.), Language competence across populations: Toward a definition of specific language impairment (pp. 63-95). Mahwah, NJ: Erlbaum.

Rice, M. L. (2004a). Language growth of children with SLI and unaffected children: Timing mechanisms and linguistic distinctions. In A. Brugos, L. Micciulla, \& C. E. Smith (Eds.), Proceedings of the 28th annual Boston University Conference on Language Development (Vol. 1, pp. 2849). Somerville, MA: Cascadilla Press.

Rice, M. L. (2004b). Growth models of developmental language disorders. In M. L. Rice \& S. F. Warren (Eds.), Developmental language disorders: From phenotypes to etiologies. Mahwah, NJ: Erlbaum.

Rice, M. L., Mervis, C., Klein, B. P., \& Rice, K. J. (1999, November). Children with Williams syndrome do not show an EOI stage. Paper presented at the Boston University Conference on Language Development.

Rice, M. L., Tomblin, J. B., Hoffman, L., Richman, W. A., \& Marquis, J. (2004). Grammatical tense deficits in children with SLI and nonspecific language impairment: Relationships with nonverbal IQ over time. Journal of Speech, Language, and Hearing Research, 47, 816-834.

Rice, M. L., \& Warren, S. F. (Eds.). (2004). Developmental language disorders: From phenotypes to etiologies. Mahwah, NJ: Erlbaum.

Rice, M. L., \& Wexler, K. (1996). Toward tense as a clinical marker of specific language impairment in English-speaking children. Journal of Speech and Hearing Research, 39, 12391257.

Rice, M. L., \& Wexler, K. (2001). Rice/Wexler Test of Early Grammatical Impairment. San Antonio, TX: Psychological Corporation.

Rice, M. L., Wexler, K., \& Cleave, P. L. (1995). Specific language impairment as a period of extended optional infinitive. Journal of Speech and Hearing Research, 38, 850-863.

Rice, M. L., Wexler, K., \& Hershberger, S. (1998). Tense over time: The longitudinal course of tense acquisition in children with specific language impairment. Journal of Speech, Language, and Hearing Research, 41, 1412-1431.

Rice, M. L., Wexler, K., Marquis, J., \& Hershberger, S. (2000). Acquisition of irregular past tense by children with SLI. Journal of Speech, Language, and Hearing Research, 43, 1126-1145.

Rice, M., Wexler, K., \& Redmond, S. (1999). Grammaticality judgments of an extended optional infinitive grammar: Evidence from English-speaking children with specific language impairment. Journal of Speech, Language, and Hearing Research, 42, 943-961.

Roberts, J. E., Mirrett, P. L., \& Burchinal, M. (2001). Receptive and expressive communication development of young males with fragile X syndrome. American Journal on Mental Retardation, 106, 216-230.

Roberts, J., Rice, M. L., \& Tager-Flusberg, H. (2000, June). Tense marking in children with autism: Further evidence for overlap between autism and SLI. Symposium on Research in Child Language Disorders, Madison, WI. 
Rice et al.: Language symptoms of developmental language disorders

Roberts, J. A., Rice, M. L., \& Tager-Flusberg, H. (2005). Tense marking in children with specific language impairment: Further evidence for overlap between autism and specific language impairment. Manuscript submitted for publication.

Rogers, S. J., Wehner, E. A., \& Hagerman, R. J. (2001). The behavioral phenotype in fragile X: Symptoms of autism in very young children with fragile X syndrome, idiopathic autism, and other developmental disorders. Journal of Developmental and Behavioral Pediatrics, 22, 409-417.

Shriberg, L. D., Tomblin, J. B., \& McSweeny, J. L. (1999). Prevalence of speech delay in 6-yearold children and comorbidity with language impairment. Journal of Speech, Language, and Hearing Research, 42, 1461-1481.

Siegal, B., Pliner, C., Eschler, J., \& Elliott, G. R. (1988). How children with autism are diagnosed: Difficulties in identification of children with multiple developmental delays. Journal of Developmental and Behavioral Pediatrics, 9, 199-204.

Smith, S. D. (2004). Localization and identification of genes affecting language and learning. In M. L. Rice \& S. F. Warren (Eds.), Developmental language disorders: From phenotypes to etiologies. Mahwah, NJ: Erlbaum.

Smith, S. D., \& Morris, C. A. (2005). Planning studies of etiology. Applied Psycholinguistics, 26, 97-110.

Spinelli, M., Rocha, A., Giacheti, C., \& Richieri-Costa, A. (1995). Word-finding difficulties, verbal paraphasias, and verbal dyspraxia in ten individuals with fragile X syndrome. American Journal of Medical Genetics, 60, 39-43.

Stark, R., \& Tallal, P. (1981). Selection of children with specific language deficits. Journal of Speech and Hearing Disorders, 46, 114-122.

Tager-Flusberg, H. (1999). A psychological approach to understanding the social and language impairments in autism. International Review of Psychiatry, 11, 325-334.

Tager-Flusberg, H. (2004). Do autism and specific language impairment represent overlapping language disorders? In M. L. Rice \& S. F. Warren (Eds.), Developmental language disorders: From phenotypes to etiologies. Mahwah, NJ: Erlbaum.

Tager-Flusberg, H., \& Anderson, M. (1991). The development of contingent discourse ability in autistic children. Journal of Child Psychology and Psychiatry, 32, 1123-1134.

Tager-Flusberg, H., \& Cooper, J. (1999). Present and future possibilities for defining a phenotype for specific language impairment. Journal of Speech, Language, and Hearing Research, 42, $1275-1278$.

Tager-Flusberg, H., \& Sullivan, K. (1995). Attributing mental states to story characters: A comparison of narratives produced by autistic and mentally retarded individuals. Applied Psycholinguistics, $16,241-256$.

Tomblin, J. B., Records, N. L., Buckwalter, P., Zhang, X., Smith, E., \& O’Brien, M. (1997). Prevalence of specific language impairment in kindergarten children. Journal of Speech, Language, and Hearing Research, 40, 1245-1260.

Tomblin, J. B., Zhang, X., Catts, H., Ellis Weismer, S., \& Weiss, A. (2004). Dimensions of individual differences in communication skills among primary grade children. In M. L. Rice \& S. F. Warren (Eds.), Developmental language disorders: From phenotypes to etiologies. Mahwah, NJ: Erlbaum.

Trauner, D., Wulfeck, B., Tallal, P., \& Hesselink, J. (1995). Neurologic and MRI profiles of language impaired children (Technical Report CND-9513). University of California at San Diego, Center for Research in Language.

Viding, E., Price, T. S., Spinath, F. M., Bishop, D. V. M., Dale, P. S., \& Plomin, R. (2003). Genetic and environmental mediation of the relationship between language and nonverbal impairment in 4-year-old twins. Journal of Speech, Language, and Hearing Research, 46, 12711282.

Volterra, V., Caprici, O., Pezzini, G., Sabbadini, L., \& Vicari, S. (1996). Linguistic abilities in Italian children with Williams syndrome. Cortex, 32, 663-677.

Wetherby, A. (1986). Ontogeny of communication functions in autism. Journal of Autism and Developmental Disorders, 16, 295-316.

Wexler, K. (1994). Optional infinitives, head movement and the economy of derivations. In D. Lightfoot \& N. Hornstein (Eds.), Verb movement (pp. 305-362). Cambridge: Cambridge University Press. 
Rice et al.: Language symptoms of developmental language disorders

Wexler, K. (1998). Very early parameter setting and the unique checking constraint: A new explanation of the optional infinitive stage. Lingua, 106, 23-79.

Whitehurst, G. J., \& Fischel, J. E. (1994). Early developmental language delay: What, if anything, should the clinician do about it? Journal of Child Psychology and Psychiatry, 35, 613648.

Zhang, X., \& Tomblin, J. B. (2000). The association of intervention receipt with speech-language profiles and social-demographic variables. American Journal of Speech-Language Pathology, $9,345-357$.

Zukowski, A. (2004). Investigating knowledge of complex syntax: Insights from experimental studies of Williams syndrome. In M. L. Rice \& S. F. Warren (Eds.), Developmental language disorders: From phenotypes to etiologies. Mahwah, NJ: Erlbaum. 